\title{
DO CONCEITO DE EDUCAÇÃO À EDUCAÇÃO NO NEOLIBERALISMO
}

\author{
Carlos Magno Augusto Sampaio* \\ Maria do Socorro dos Santos** \\ Peri Mesquida***
}

\section{Resumo}

Neste texto procuramos percorrer os caminhos da história da educação no Brasil, iniciando com uma reflexão sobre os sentidos atribuídos à educação, para pensar, também, os rumos que ela foi obrigada a seguir e as formas que a fazem assumir, em particular, nesses tempos de neoliberalismo.

\section{Résumé}

Dans ce texte nous cherchons de parcourir les chemins de l'histoire de l'éducation au Brésil, dès l'époque de la colonisation. Nous faisons dans le chapitre I une réflexion sur les concepts d'éducation, et après, dans le chapitre II, nous essayons de cerner les manoeuvres faites pour la faire répondre aux temps neolibérales. Nous finissons le texte par um aperçu de la situation de l'éducation dans le pays lorsqu'il acepte de servir au neolibéralisme.

\section{Introdução}

A palavra educação possui conceitos diversos e diferentes. Para chegarmos aos conceitos é importante que partamos da etimologia da palavra. Assim, podemos dizer que a palavra "educação" tem origem em termos latinos, tais como os verbos "educare" e "educere". Este último vem de "ex ducere", que significa, literalmente, conduzir (à força) para fora; o primeiro, vem de "educare"que significa amamentar, criar, alimentar, por isso mesmo se

\footnotetext{
* Mestrando em Educação PUCPR.

Email: carlosmagno.Sampaio@bol.com.br

** Mestranda em Educação PUCPR.

Email: mspross@uol.com.br

** Professor/Pesquisador - PPGE(PUCPR).

Email: peri@rla13.pucpr.br
} 
aproxima do vocábulo latino "cuore"(coração). Daí, a palavra "caridade": oferecer algo que vem do coração. É possível, então, chegar a duas expressões práticas da ação de "educar": de um lado, a idéia de conduzir, impondo uma direção, o que a aproxima de "ensino" - introjetar a sina, o destino de alguém; de outro lado, a idéia de oferta, dádiva que alimenta, possibilitando o crescimento (Ver: FULAT, 1994). Dessa forma, podemos chegar à "pedagogia". Na Grécia, a "paidagogía" (paidós agein) era atividade exercida pelo "paidagogós" - aquele que conduz as crianças (o espanhol antigo usava a palavra "crianza" para significar a tarefa de educar. Denotava a ação de alimentar, proteger os filhos que não podiam alimentar-se ou proteger-se por si mesmos, precisando do auxílio de um adulto). Por esse motivo, escrevia VARRÓN: "Educit obstetrix, educat nutrix, instituit pedagogus, docet magister" ("A parteira traz à luz, a ama de leite alimenta, o pedagogo instrui, o mestre ensina").

Creio que é possível afirmar que a educação é aquilo que alguém conquistou ao fim de um processo em que interagem a prática e a teoria, a teoria e a prática, a ciência e a técnica (tekne), o saber e o fazer. É um processo de vida, de construção, de experimentação. A rigor, é a passagem do ser para o dever-ser. A educação tem, portanto, uma conotação lógica alimentada por uma ação teleológica, num processo pleno de intersubjetividade.

A educação escolar, isto é, aquela educação veiculada por uma instituição de ensino, é uma "peça chave na montagem jurídica de filiação simbólica que toda sociedade precisa para ser, existir e conviver - uma forma particular de como uma sociedade se institucionaliza com o auxílio da escola" (LEGENDRE, 1994, lição III).

Desde que o homem é homem a educação se apresenta como um elemento fundamental da construção da comunidade e da subjetividade. A educação se operacionaliza na medida em que constrói e reconstrói a cultura, constrói e democratiza saberes, inclui atores, rememora a história, mitos e ritos e projeta sinais da sociedade futura que ela ajuda a edificar, costurando atos e pactos no tecido social.

Aquele que procura a instituição escolar para nela se matricular, pertence, antes de ser um membro da escola, a um corpo social que inclui a família e a comunidade da qual se origina e da qual participa. A escola irá somar-se a esses organismos da sociedade para auxiliar o educando a construir a sua cidadania, isto é, a sua inserção na sociedade de forma madura e consciente. Por isso, a "missão" conferida à escola é não só apaixonante, mas, também, política. Apaixonante porque sem a imersão dos atores do processo educativo na tarefa de educar e de se educar, mergulhando na construção de um projeto de vida, não é possível "fazer" educação. É política, no sentido de que ela irá auxiliar na construção da "polis" enquanto "civitas", a comunidade dos "cidadãos"; talvez por isso mesmo, a tarefa de fazer educação apaixona e desafia.

Para Jean-Paul SARTRE (1968), a história é a conquista da liberdade, 
Do conceito de educação à educação no neoliberalismo

num enredo que envolve amor e ódio, discórdia e concórdia, guerra e paz, vitórias e derrotas. A educação, em especial a escolar, tem também produzido uma história de amor e de conflitos ao longo da qual a sua ação qualificadora cuja meta seria gerar igualdade, produziu posições socialmente diferenciadas, carregadas de elitismo e exclusão, como diz FRIGERIO (1973).

A escola que tem sido questionada até quanto à necessidade de sua existência tal qual ela se apresenta (ILلCH, 1973), é, também, contraditoriamente, chamada a não deixar esmorecer a esperança de dias melhores para a sociedade humana.

A educação, vocacionada a ser o motor por excelência do acesso e do manejo da palavra falada (FREIRE, 1974), escrita e lida, não somente prepara cidadãos capazes da denúncia de injustiças e do anúncio da Boa Nova, solidária e transformadora, como pode e deve ser fonte da palavra que provoca rupturas epistemológicas e conflitos sócio-cognitivos. Nesse sentido, podemos dizer que a escola, por meio da educação, deve oferecer a possibilidade de que o "socialmente significativo se articule com o subjetivamente significativo" (FIRGERIO, 1999).

Isso faz com que os agentes escolares não esqueçam de, constantemente, levar em consideração a experiência e o pensamento do educando, pois ele é um ser-no-mundo, vindo de uma comunidade que o gerou e o dotou de uma bagagem cultural que não pode ser esquecida pelos agentes educativos da escola no momento de ser trabalhado o processo de ensinoaprendizagem. A intersubjetividade entre educando e educador se realiza quando o educador reconhece no educando um ser que não é uma "tábula rasa", uma folha de papel em branco, mas possui uma densidade de conhecimento, a partir do qual tem início a educação escolar. Se a escola acredita possuir o monopólio do saber, torna-se autoritária e transmissora do saber dominante. Alimentar a reciprocidade e a troca está na essência da aprendizagem.

Assim, se a instituição escolar, por meio da educação, realiza a articulação do social com o subjetivo, permitindo que um penetre o outro numa combinação dialética de dinamismo interno e externo, ela estará correspondendo aos anseios daqueles que apostam na sua necessidade e permanência enquanto fermento de uma sociedade melhor.

Isso implica em fazer da prática pedagógica uma ação vivida todos os dias, conjugando as experiências dos atores que fazem parte do processo de aprendizagem, somando saberes e transformando-os em conhecimento (LATERZA, 1971).

Dessa maneira, é possível pensar a instituição escolar e a educação que ela socializa, como catalisadoras das transformações sonhadas, das inovações projetadas e das tradições que devem ser preservadas, pois educador e educando são partícipes da mesma ação, digamos, pedagógica; aquele não é um mero funcionário, e este não se reduz a um cliente. 
Assim, os projetos que são pensados no interior da instituição escolar são gerados num campo de tensão entre o dado que pretende se manter e 0 por vir que deseja nascer, aparecer, vir à luz. São os projetos construídos nas instituições escolares que as definem e anunciam suas imagens, seus símbolos, suas características próprias, mas são também os atores que nelas desempenham papéis dos mais diversos níveis no drama do cotidiano que embutem nos projetos sua vivência, sua identidade, suas interpretações da realidade. É aí que aqueles que nelas militam esculpirão com seus cinzéis os matizes do futuro da instituição, aquiescendo, completando, enriquecendo os projetos, ou criando obstáculos à sua efetivação.

Tudo isso faz parte do "jogo" tenso entre o individual e o coletivo, o novo e o velho. Mas é da tensão que nasce o novo. Do encontro da expressão dos pensamentos escondidos, às vezes de forma clara, outras, nem tanto, de cada um, nasce a construção do saber que irá dar vida à instituição.

Essa construção coletiva engendra a filiação de cada um e de todos à instituição e seus projetos, aos projetos e sua instituição, uma filiação social, simbólica, que faz de cada um "socius" dos projetos quando estes se expressam em forma de programas concretos, isto é, quando eles deixam de ser letra sobre o papel e tornam-se vida nas instituições.

Por isso, a prática pedagógica, digamos interativa, levaria em conta as diferenças, as individualidades, as subjetividades que totalizam a comunidade escolar. Consideraria, ainda, as tensões que afluem a cada instante no interior da comunidade. Mas, também, é fundamental que se reflita de forma clara a identidade e a natureza das instituições que a constroem e a concretizam no cotidiano da sua existência escolar. Sem se dar conta desses elementos, uma prática pedagógica escolar tende a provocar um consentimento interno artificial e uma rejeição subjetiva nem sempre manifestada, o que leva os atores a renegarem a ação transformadora em favor do ativismo improdutivo e enfadonho.

\section{A educa ção no mundo, hoje: o impacto do neoliberalismo}

Há aproximadamente cento e cinqüenta anos, Marx e Engels escreveram que a lógica do sistema capitalista levaria o próprio sistema, de crise em crise, para o caos. Disseram eles: "a transformação contínua da produção, 0 abalo incessante de todo o sistema social, a insegurança e o movimento permanentes distinguem a época burguesa de todas as demais...Tudo o que é sólido desmancha no ar, tudo o que é sagrado é profanado...Ao invés das necessidades antigas, satisfeitas por produtos do próprio país, temos novas demandas supridas por produtos dos países mais distantes, de climas os mais diversos. No lugar da tradicional auto-suficiência e do isolamento das nações, 
surge uma circulação universal, uma interpendência geral entre os países. As relações de troca e as relações burguesas de produção, as relações burguesas de propriedade, a moderna sociedade burguesa, que fez surgir como que por encanto possantes meios de produção e de troca, assemelha-se ao feiticeiro que já não pode controlar as potências infernais por ele postas em movimento" (MARX; ENGELS, 1999). Na realidade, a previsão que esta citação contém, cumpre-se nos dias de hoje, materializando-se no que se convencionou chamar de sociedade pós-industrial.

A "sociedade pós-industrial" se contrapõe ao modelo denominado de "fordista-keynesiano" de produção, o qual se caracteriza pelo fato de consubstanciar-se em uma base técnica desqualificada, parcializada e repetitiva. Assim, o capital direciona-se para o "toyotismo", isto é, uma nova base técnica "produtiva seriada, flexível e diferenciada, incluindo a terceirização dos serviços com o desenvolvimento de novas tecnologias de ponta, entre as quais, a biotecnologia, a microeletrônica, a informática e a telemática”. Essa modalidade produtiva garante, assim, a reprodução e a acumulação de capital, como forma de superar a perda de lucratividade, advinda do período de estagnação econômica mundial e, principalmente, dos países desenvolvidos, causada pela crescente dívida externa dos países do assim chamado "terceiro mundo", transformados anteriormente pelo sistema capitalista em exportadores de capital.

Como suporte político-ideológico, o capitalismo resgatou o pensamento do grupo de Mont Saint-Pélérin, na Suíça, liderado por Friedrich von Hayek, que ajuntou outros filósofos, economistas e cientistas políticos, como Karl Popper, Ludwig von Moses e o casal Milton e Beth Friedman. Esse pensamento é sintezado na obra de Hayek, "O Caminho da Servidão", escrita em 1944. O prêmio Nobel concedido ao autor, em 1974, já é revelador das transformações que, a partir dessa década, ficaram conhecidas pelo nome de "neoliberalismo".

As recomendações do Grupo "preconizavam uma reforma do Estado que colocava em xeque o Estado de Bem-Estar social europeu, bem como a política norte-americana do denominado "New Deal", nas suas variações keynesianas"(FREITAS, 2002).

O economista inglês, John M. Keynes, opunha-se ao liberalismo em dois aspectos: primeiro, desconfiava do livre-mercado que considerava insuficiente para regular sozinho os problemas do emprego, das crises econômicas do capital e do crescimento; segundo, a idéia de que, no mercado, a demanda é determinante da oferta. Por isso, o nível de produção e emprego é determinado pela demanda efetiva, ou seja, a previsão que fazem os empresários sobre a procura dos consumidores de seus produtos. Dessa maneira, os keynesianos defendiam uma ação sobre a demanda, pelas demandas do Estado e estímulos ao crédito para o crescimento econômico, mesmo que isso gerasse déficits orçamentários e inflação aos governos. Assim, "só o Estado 
tem na sociedade humana o interesse e o poder de atuar sobre o todo da economia do país...através de técnicas que não exigem a implantação do socialismo...e assim salvou a democracia... fez uma revolução na democracia e pela democracia"(GALVES, 1991).

Além de Hayek, cuja influência se estende pela Europa Ocidental, o novo combate contra o "império do mal", o comunismo, ou a servidão humana, encontra o correspondente para a América Latina em Milton Friedman, monetarista da escola de Chicago, numa de suas obras mais importantes, "Capitalismo e Liberdade". Nessa obra, Riredman horroriza-se com o Estado de bem-estar social, que interfere na esfera da liberdade individual, pois o papel do governo, além de coibir as emissões de moeda que geram inflação, dever ser 0

de um governo que mantenha a ordem e a lei; defina os direitos de propriedade; sirva de meio para a modificação dos direitos de propriedade e de outras regras do jogo econômico; julgue disputas sobre a interpretação das regras; reforce contratos, promova a competição; forneça uma estrutura monetária; suplemente a caridade provada e a família na proteção do irresponsável, quer se trate de um insano ou de uma criança. Um tal governo, teria, evidentemente, importantes funções a desempenhar, visto que, o liberal consistente, não é um anarquista (FREITAS, 2002).

Podemos dizer que a América Latina foi testemunha da primeira experiência neoliberal do mundo, no Chile, de Pinochet, em 1973. Começou seus programas de maneira dura, com desregulamentações, desemprego massivo, repressão sindical, redistribuição de renda em favor dos ricos e privatização de bens públicos, tendo como pressuposto "a abolição da democracia e a instalação de uma das mais cruéis ditaduras militares do pós-guerra" (ANDERSON, 1997).

Em 1979, com Tatcher, na Inglaterra e em 1980, no governo Reagan, nos Estados Unidos, o neoliberalismo será experimentado naqueles países. Diz ANDERSON (1997) "que o governo Tatcher se lançou num amplo programa de privatização, começando por habitação pública e passando em seguida à indústrias básicas, como aço, a eletricidade, o petróleo, o gás e a água”.

Em 1989, um grupo de neoliberais representativos dos países centrais do capitalismo reuniu-se em Washington com representantes do Banco Mundial, do FMI e do BID e com representantes da América Latina. A reunião foi promovida pelo Institute from International Economics, tendo como tema “Latin American Adjustment: How much has happened?". Visava a fazer uma avaliação das reformas econômicas realizadas em países da América Latina. $\mathrm{O}$ documento oficial do encontro recebeu o nome de "Consenso de Washington", com dez itens principais: "disciplina fiscal; priorização dos gastos públicos; reforma tributária; liberalização financeira; regime cambial; liberalização 
comercial; investimento direto estrangeiro; privatização; desregulação e propriedade intelectual"(BATISTA, 1994).

O objetivo do "Consenso" era o de eliminar toda concorrência estrangeira da América Latina, a fim de manter, para os Estados Unidos, a área como um mercado importante para a superprodução industrial americana e investimentos privados, "explorando as grandes reservas de matérias-primas e afastando o comunismo internacional" (CHOMSKY, 1999).

No entanto, era necessário planetarizar o "consenso". O neoliberalismo promove fundamenta, então, um movimento a partir de Washington, denominado de "globalização". A idéia básica é a de que o mundo possui um centro, os Estados Unidos, a partir do qual são difundidas idéias, cultura, concepções de mundo, tecnologia, a ideologia do mercado...

Hayek, na sua obra "The constitution of liberty" (1960), diz que 0 mercado é uma instituição "espontaneamente" ordenada que evolui naturalmente. O mercado não é produto da inteligência humana (seria da inteligência divina?). Afirma que o mecanismo de preços do "livre" mercado oferece informações importantes para que funcione acertadamente a lei da oferta e da procura. Além disso, Hayek atribui importância ao individualismo, ao homo economicus, fundado nas idéias de individualidade, racionalidade egoísmo. Essas idéias, transformadas em práticas econômicas e políticas, estabelecem políticas em países em desenvolvimento caracterizadas por cortes nos gastos públicos em serviços, notadamente nas áreas da educação, da saúde e da infra-estrutura sanitária (esgotos, água tratada, etc.), bem como nas ações governamentais em favor da habitação (CARNOY, 1995).

É claro que os países ricos, como os da Comunidade Européia, já têm condições para ajustarem-se e responder às rápidas mudanças implantadas nas comunicações e na tecnologia, mas os países em desenvolvimento, respondem às "exigências" da era da globalização cortando gastos na área social. Além disso, o FMI e o Banco Mundial impõem políticas de ajustes estruturais aos países em desenvolvimento como resposta aos seus contínuos problemas com o pagamento dos juros da dívida externa.

Dentre essas políticas, temos a privatização, a redução do tamanho do Estado, redução da dívida interna acumulada, e encorajamento do investimento externo. A privatização representa, também, a liberação de compromissos do Estado, a tecnização das empresas (com o conseqüente desemprego) e, é claro, a redução dos serviços prestados pelo Estado.

Finalmente, o neoliberalismo indicaria o seguinte:

1. Os indivíduos são responsáveis, pois são agentes morais, daí a individualidade, a racionalidade, o egoísmo.

2. Administração para o gerenciamento = liberdade para gerenciar.

3. Desgovernamentalização do Estado: o governo estaria atrelado ao mercado. 
4. Nova relação entre governo e conhecimento: governo à distância (ministérios, secretarias de Estado de educação à distância, etc.).

5. Mercantilização da democracia (venda de candidatos como produtos da imagem; eleitores tornam-se consumidores individuais passivos).

6. Socialização das perdas.

7. Desenvolvimento de uma sociedade empresa: privatização do público, mercantilização da educação e da saúde.

8. Baixa consciência ecológica, pois o que determina as ações econômicas é o lucro máximo, não havendo qualquer limite para o crescimento soluções de mercado para problemas ecológicos.

9. Nenhum controle nacional sobre o capital.Este estaria sendo monitorado pelas agências internacionais "globalizadas": FMI, BM, Organização Mundial do Comércio (GATT).

Dessa maneira, os países que adotam as políticas do Consenso de Washington teriam refletidas nas suas ações educacionais, o seguinte:

1. Afastamento do Estado como agente financiador da educação.

2. Privatização das instituições públicas de ensino.

3. Ênfase sobre a avaliação e controle - Estado avaliador e controlador (PROVÃO, ENEM, etc.).

4. Critérios essencialmente quantitativos para selecionar professores e alunos, bem como para avaliar cursos nos diversos níveis do ensino.

5. Ênfase sobre a prática em detrimento da teoria.

6. Tecnização das ações educativas.

7. Enfase sobre os fins a serem atingidos, pois estes justificam os meios.

8. Preparação escolar profissionalizante e técnica para atender à demanda das empresas (pós-médio, institutos de educação, cursos normais superiores, etc.)

9. Formação rápida e à distância. Formação esta oferecida, geralmente, por agências de mercantilização do ensino.

10.Fetichização da educação.

11.A educação precisa trabalhar com a idéia de que vivemos numa "sociedade do conhecimento", e a língua oficial dessa sociedade, isto é, seu "quadro vocabular", está "digitado" em inglês: "soft-ware", "knolowdge workers", "boom", "hard-ware", "delet", etc.

O quadro acima dá uma idéia do reflexo do neoliberalismo sobre a educação. É significativo que na década de 1980, diversos países europeus empreenderam reformas do ensino, procurando adaptar-se rapidamente aos "novos tempos".

Percebemos, até pela terminologia utilizada, que tudo se transforma em mercadoria. A educação vira um negócio e, em muitos casos, altamente 
rentável, disputado pela proliferação de organizações particulares que não visam senão ao lucro, pois "a reforma do Estado pretende modernizar e racionalizar as atividades estatais, redefinidas e distribuídas em setores, um dos quais é designado setor dos serviços não-exclusivos do Estado, que é a educação"(CHAUÍ, 1999).

Portanto, o direito à educação passa a ser considerado como um serviço definido pelo mencado. A lógica do modelo é a de que as instituições de ensino passem a responder a diversas necessidades que lhe são externas, tornado-se, "cada vez mais, organizações multifuncionais, indispensáveis e utilitárias" (FREITAS, 2002).

Assim, quando

razão, verdade, história são tidas por mitos, espaço e tempo se tornaram a superfície achatada de sucessão de imagens, pensamento e linguagem se tornaram jogos, constructos contingentes cujo valor é apenas estratégico (então) essa instituição não forma e não cria pensamento, despoja a linguagem de sentido, densidade e mistério, destrói a curiosidade e a admiração que levam à descoberta do novo, anula toda a pretensão de transformação histórica como ação consciente dos seres humanos em condições materialmente determinadas (CHAUÍ, 1999).

\section{A educação no Brasil sob o neoliberalismo}

O processo de escolarização no Brasil remonta à expedição colonizadora de Tomé de Souza. Pode, portanto, ser datada: 1549. Foi neste ano que chegaram ao nosso País seis padresjesuítas, comandados pelo Padre Manoel da Nóbrega. Chegaram no concerto de uma política da Coroa portuguesa de pôr em prática uma "nova política colonizadora estabelecida por El-Rei Dom João III, nos regimentos de 17 de dezembro de 1548, a saber: defender 0 litoral, policiamento interno e fundação de núcleos estáveis e fortificados de colonizadores". Os jesuítas vinham zelar pela fé católica dos conquistadores, impedir a presença e proliferação da heresia protestante, ensinar os filhos dos colonos, justificar as ações das autoridades portuguesas e domesticar os nativos, se possível, convertendo-os. Na realidade, chegaram e se impuseram sem luta ideológica. Houve, a rigor, um silêncio que se impôs por centenas de gerações. Isso porque não foram elaborados estudos críticos sobre a posição dos jesuítas. No fundo, o silêncio que se impôs era com relação às idéias contrárias, até porque o seu pensamento e a sua concepção de mundo foram repetidas e o são até agora. As poucas críticas ouvidas foram: eles são cobiçosos e injustos. Cobiçosos, porque queriam instalar um império temporal na América Latina; injustos, porque não trataram os índios com equanimidade. 
Os jesuítas centraram o seu trabalho em um ponto considerado neutro: a educação. Isso porque a educação transmite um saber que é visto como sendo para o bem de todos.

Percebemos entre os primeiros educadores/catequizadores uma grande preocupação com o quantitativo: “Já batizamos cem pessoas pouco mais ou menos... E haverá seiscentos ou setecentos catecúmenos para batizar em breve os quais aprendem muito bem..." (Nóbrega - Cartas do Brasil, 10 de agosto de 1549). Esse quantitativismo aparece ligado a duas razões: primeira, pela conjuntura histórica - a construção de estados nacionais modernos acarreta a substituição dos laços de dependência pessoais e passa do momentâneo, do eventual para o duradouro e o permanente. O mercantilismo, economia monetária, leva a uma ideologia econômica que pensa por meio de quantidades, preços, custos, valores, estoques, moedas, etc.(GODINHO, 1963); a segunda, tem a ver com a própria ordem dos jesuítas cujo pensamento se liga à necessidade de tudo contabilizar, preencher, para não deixar espaços vazios que poderiam vir a ser ocupados pelas forças do mal, como podemos ver nos Exercícios de Loyola (BARTHES, 1971). Afinal, "mente desocupada, oficina do diabo..."

Na realidade, as práticas pedagógicas dos jesuítas têm uma história que de certa forma se confunde com a história do Ocidente, a história política, social, econômica e da formação e difusão das ideologias ou das correntes de pensamento.

Creio que é esclarecedor pensar a história da Companhia de Jesus como uma missão. A missão tem a ver com as ordens seculares ou terceiras que vão para as fronteiras pregar a fé, entregar uma mensagem aceita como originada de Deus. A língua do Deus que conclama para a missão é uma só o latim - pois a multiplicidade de línguas é vista como a Babel, uma maldição. Para os jesuítas, era fundamental que a língua fosse ouvida, pois somente assim haveria conversão. Essa luta contra o vulgar, o bárbaro, o protestantismo, o demônio, o mal. A palavra é fundamental para converter. Afinal, "Eu sou o Verbo..." O saber que a palavra veicula não é um saber qualquer, confunde-se com o saber da religião cristã, portanto, vem de Deus (MESQUIDA, 2002).

A base teórica, epistemológica desse saber é o tomismo-aristotélico, materializado em prática pedagógica no "ratio studiorum", o plano de "estudos racionais".

A concepção de educação originada do "plano de estudos racionais" constitui-se em um monólogo pedagógico fundado na autoridade do mestre, detentor do saber, pois, na medida em que os primeiros mestres eram clérigos, o saber do qual estavam investidos, vinha do próprio Deus. Ao discípulo (aquele que repete o que outro diz), cabe somente a tarefa de apreender 0 conhecimento transmitido e, eventualmente, dar resposta às questões apre- 
sentadas pela autoridade pedagógica (uma "pedagogia da resposta"). A "resposta" final, no entanto, é prerrogativa do mestre, adulto acabado - potência atualizada. Ele é o escultor que possui a idéia da obra. $\mathrm{O}$ aluno (aquele que é destituído de luz) é visto como uma folha em branco sobre a qual será impresso o carimbo do saber - um elemento passivo que se con-formará pouco-apouco ao modelo que está na mente do mestre...

A ação pedagógica está, portanto, centrada no mestre-escultor, ou impressor. Este manipulando com "maestria" a linguagem, procurará "imprimir" no discípulo, con-vencendo-o com argumentos inquestionáveis, o saber do qual ele, mestre, é o guardião (não esquecer que o mestre não repassa ao discípulo todo o saber que ele possui, pois o aluno é sempre uma aparência imperfeita do modelo do qual se originou, e também, porque o discípulo não pode vir a ser, de repente, superior ao mestre). O discípulo somente apreende, adquire conhecimento, sem participar da sua elaboração. Ele é uma matéria informe que aguarda o momento de ter as suas potencialidades "estimuladas" pelas "ferramentas" do mestre. Este dará à "matéria" a forma cujo modelo está no seu pensamento (ou livro texto). Assim, o aluno diante do mestre, guardião do saber, não é senhor de si mesmo e menos das suas opiniões.

Dessa maneira, a ação pedagógica dos jesuítas, fundada numa cultura transplantada, atuou no sentido de auxiliar o colonizador a manter o domínio e a introjetar no colonizado o conformismo. O ensino que se baseava no latim, na literatura clássica e na retórica, destituído de qualquer sentido crítico, contribuiu para aumentar a distância entre os que sabiam e os que não tinham a possibilidade (condições materiais e sociais) de "adquirir" o saber. $\mathrm{O}$ dualismo colégio para os ricos e escolas de ler e escrever para os pobres (futuros liceus de artes e ofícios) avalizou a distinção que se estabelecia entre a elite (os que tinham posses e detinham o saber) e o povo (os destituídos).

Não há dúvida de que o tipo de escola fundada no tomismo-aristotélico e na pedagogia dos jesuítas consolidou no Brasil uma educação centrada no professor, autoridade máxima no processo pedagógico, porque detentor do saber acumulado. Sua tarefa seria a de dar forma à matéria-prima (o aluno): atualizar as potencialidades. Isso se realiza por meio de um discurso bem articulado, lógico, inquestionável: um verdadeiro monólogo, pois o ensino é a transmissão do conhecimento do adulto para os jovens (em formação).

Na medida em que o aluno é um recipiente passivo do conhecimento, cuja atividade única é a memorização, a ação do pensar e refletir fica prejudicada - inibindo a criação e, portanto, estimulando a formação de consumidores em detrimento da criação e da produção. Com isso, o ensino nada mais é do que mera reprodução do saber acumulado sem que eles, como agentes do processo educativo que deveriam ser, participem da sua elaboração.

Essa ação pedagógica (melhor seria chamar de ato pedagógico) contribuiu para manter o vínculo entre a oligarquia e o modo de produção que a 
alimenta, mantendo ao mesmo tempo, vícios que perduram até hoje, inibem a nossa capacidade de criar e produzir, porque não valoriza a iniciativa, a curiosidade intelectual, a observação, a reflexão, a crítica, a pesquisa (MESQUIDA, 2002).

Consumidores de modelos transplantados, nos conformamos a ser meros receptores e reprodutores, incapazes de pensar e de inovar: dependentes.

Se a concepção social de mundo positivista acrescentou mais elementos conservadores à nossa prática educativa e auxiliou a fragmentar 0 saber e a impor o tecnicismo quantitativista, auxiliou, também, a imposição do neoliberalismo dominante no pensamento educacional oficial brasileiro.

É "pedagógico" relembrarmos outro texto de Marx e Engels, esse sobre educação ensino no capitalismo do futuro: "O verdadeiro significado da educação, para os economistas filantropos, é a formação de cada operário no maior número de atividades industriais, de tal sorte que se é despedido de um trabalho pelo emprego de uma máquina nova, ou por uma mudança na divisão do trabalho, possa encontrar uma colocação o mais rápido possível" (MARX e ENGELS, 1983). Frigotto comentando essa passagem dos "Textos", diz que a tese da sociedade do conhecimento transforma o proletário em cognitário. Na realidade, quando se fala em sociedade do conhecimento, querem os seus propagandistas mascarar a divisão da sociedade em classes sociais, pois querem difundir a idéia de que a divisão não é mais política, social, econômica, mas cognitiva, do saber.

A ideologia da "sociedade do conhecimento" está intimamente vinculada, no Brasil, à teoria do capital humano, a qual concebe a educação como um bem de consumo. A instituição escolar oferece um produto que 0 cliente, consumidor, irá adquirir na "convicção" de que estará investindo em si mesmo, na sua ascensão social. A educação é vista como uma mercadoria a ser adquirida, proporcionando acesso a outras mercadorias vendidas no mercado:

as intenções claramente explícitas tanto na legislação quanto no planejamento educacional se expressam na ênfase dada à educação como Human capital que promove o desenvolvimento. Com o investimento em educação se quer obter crescimento econômico. A política e a teoria educacional que focalizam a educação desta perspectiva omitem que essa utilização da educação como reprodutora da força do trabalho não gera crescimento econômico em geral, nem se reverte em taxa de retorno individual, mas provoca uma dinamização das relações de trabalho, que garante maior taxa de maisvalia, apropriada por uma minoria. As intenções explícitas da política educacional brasileira consistem em assegurar taxas de lucro cada vez maiores para esta minoria, constituída das classes dominante e média alta (FREITAG, 1986). 
Podemos concluir que, para o pensamento neoliberal, o êxito para 0 homem não se baseia na cooperação ou "solidariedade, mas no triunfo calcado na competição com os outros", pois, o homem é, hoje, mais do que nunca, o lobo do homem...

A escola, nesses tempos de globalização, está sendo chamada pela sociedade a superar a ideologia neoliberal que lhe está sendo imposta como algo global da qual ela não tem condições de se safar. Urge, portanto, que o conformismo que nos vem dos tempos do Brasil colônia seja combatido pela intransigência em aceitar o estabelecido como sendo a última palavra.

\section{Referências}

ANDERSON, P. Balanço do neoliberalismo. São Paulo: Paz e Terra, 1995. BATISTA, P.N. Uma nova moeda sobe ao cadafalso. Folha de São Paulo, São Paulo, 30 nov. 2000.

CARNOY, M. Educação. Estado e desenvolvimento econômico. São Paulo: Cia. das Letras, [199?].

CHAUÍ, M. Universidade em liquidação. Folha de São Paulo, São Paulo, 11 jul. 1999.

CHOMSKY, N. A sociedade global: educação, mercado e democracia. Blumenau: Editora da Furb, 1999.

FREIRE, P. Conscientización. Buenos Aires: Búsqueda, 1974.

FREITAG, B. Escola, Estado e Sociedade. São Paulo: Moraes, 1986.

FREITAS, F. J.Correia de. Neoliberalismo e educação no Brasil: 0 impacto sobre a educação superior pública, no período de 1993 a 2000. Curitiba, 2002. 144 f. Dissertação (Mestrado) - Pontifícia Universidade Católica do Paraná.

FRIGERIO, L. Identidade e projeto. Piracicaba: Editora da UNIMEP, 1999.

FRIGOTTO, G. A produtividade da escola improdutiva. São Paulo: Cortez, 1984.

FULATT, O. Filosofia da educação. Petrópolis: Vozes, 1994

GALVES, C. Manual de economia política atual. São Paulo: Atlas, 1991.

GODINHO, F. Governo investe apenas 33\% do previsto. Folha de São Paulo, São Paulo, 24 dez. 1999. 
ILLCH, I. Uma sociedade sem escolas. [S. l.: s. n.], 1973.

LATERZA, LF. Filosofia da educação:fundamentos. São Paulo: Herder, 1971.

LEGENDRE, P. Leçons. Paris: Fayard, 1994.

MARX \& ENGELS. O Capital. Rio de Janeiro: Civilização Brasileira, 1983.

MARX \& ENGELS. O manifesto comunista. Petrópolis: Vozes, 1999.

MESQ UIDA, P. Hegemonia norte-americana e educação protestante no Brasil. São Paulo: Editeo, 1994.

SARTRE, J.-P. La nausée. Paris: Livres de Poche, 1968. 